\title{
Editorial: Pathways Towards Negative Emissions in Industry
}

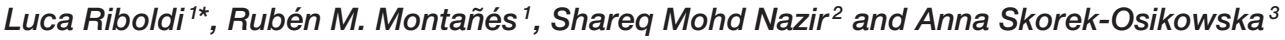 \\ ${ }^{1}$ Gas Technology, SINTEF Energy Research, Trondheim, Norway, ${ }^{2}$ Department of Chemical Engineering, KTH Royal Institute \\ of Technology, Stockholm, Sweden, ${ }^{3}$ Faculty of Power and Environmental Engineering, Silesian University of Technology, \\ Gliwice, Poland
}

Keywords: climate change, negative emission technologies, industry, negative emissions, $\mathrm{CO}_{2}$ capture, $\mathrm{CCS}$ industrial processes, carbon dioxide removal

\section{Editorial on the Research Topic}

\section{Pathways Towards Negative Emissions in Industry}

As the carbon budget is rapidly diminishing, realistic roadmaps to meet global mitigation targets necessarily rely more and more on negative emissions (IPCC, 2018). Industry presents significant challenges to reduce emissions down to zero and beyond, while remaining competitive (Leeson et al., 2017). Energy efficiency and electrification can only deliver partial decarbonization of industrial production but fail to address issues such as the supply of high temperature heat and the presence of inherent process emissions. Additional options like fuel and feedstock switching and $\mathrm{CO}_{2}$ capture might be considered to reach negative emissions. The specificity of the various industrial processes necessitates the development of a portfolio of technological solutions. Finally, a whole value chain perspective for capture, transport, and storage is necessary to estimate negative emissions in industry.

Krishnamurthy et al. (2021) evaluate the performance of 3D printed sorbent containing polyethyleneimine (PEI) and multiwalled carbon nanotubes to capture $\mathrm{CO}_{2}$ from flue gas in a power plant that uses biomass as fuel. Breakthrough experiments reveal that $3.6 \mathrm{~mol}$ of $\mathrm{CO}_{2}$ per $\mathrm{m}^{3}$ of sorbent can be captured at $70^{\circ} \mathrm{C}$, whereas the adsorption capacity was observed higher at 80 and $90^{\circ} \mathrm{C}$. Experimental results are used to model and optimize a six-step vacuum swing adsorption (VSA) process with minimum energy requirement to capture $90 \% \mathrm{CO}_{2}$ with $95 \%$ purity. In the feed, $15 \% \mathrm{CO}_{2}$ is more suited in the six-step VSA process, resulting in $0.6 \mathrm{MJ}$ of electricity demand per $\mathrm{kg} \mathrm{CO}$ captured and $2.2 \mathrm{~mol} / \mathrm{m}^{3}$-adsorbent.

Carbon dioxide capture with further storage can be applied to several existing industrial processes and thereby contribute to negative emissions. The study by Svensson et al. (2021) analyses a novel calcination process, applied to the pulp and paper industry, that uses electric gas-plasma technology combined with steam slaking in two kraft mills. The aim of this study is to evaluate its potential combination with CCS from the calcination plant. The potential reduction of greenhouse gas emissions depends strongly on the emissions intensity and fuel type used. As the results show, avoided $\mathrm{CO}_{2}$ emissions can be significant, reaching $50 \mathrm{kt} / \mathrm{a}$ for a mill of $400 \mathrm{kt}$ pulp per year and almost $100 \mathrm{kt} / \mathrm{a}$ for the mill of $700 \mathrm{kt}$ pulp, respectively. By electrifying the calcination process further emission reductions are possible through CCS. Capture potential is than equal to $95 \mathrm{kt} / \mathrm{a}$ (for a $400 \mathrm{kt}$ mill) and $164 \mathrm{kt} / \mathrm{a}$ (for a $700 \mathrm{kt}$ mill), and CCS costs reach 36-60 EUR/tCO .

Enhanced weathering is a carbon dioxide removal (CDR) measure that consists of accelerating the natural chemical weathering processes of rocks, which sequesters atmospheric $\mathrm{CO}_{2}$ through alkalinity production. A feasible feedstock for enhanced weathering consists of the large quantities of mine tailings produced by the global mining industry. The study by Bullock et al. (2021) assesses the global CDR potential of this concept. A global database of mined metal and diamond commodity tailings was established. From the database a theoretical CDR capacity in the range between 1.1 and $4.5 \mathrm{Gt} \mathrm{CO}_{2}$ per year was estimated. However, dissolution 
rate considerations suggest that only a fraction (up to a maximum of $21 \%$ ) of such potential may be realised on a relevant timescale. Yet, those figures demonstrate that enhanced weathering might substantially contribute to delivering negative emissions in an industry that annually emits about $3.6 \mathrm{Gt}$ of $\mathrm{CO}_{2}$.

Tiefenthaler et al. (2021) present a proof of technology for the industrial scale negative emissions value chain in the concrete sector specific to Switzerland, with focus on sequestration of $\mathrm{CO}_{2}$ in the form of calcium carbonate in the recycled concrete aggregate (RCA). The $\mathrm{CO}_{2}$ for carbonation is assumed to be derived from upgrading of biogas produced from anaerobic digestion of bio waste. Lab-scale experiments revealed that $7.2 \mathrm{~g}$ $\mathrm{CO}_{2}$ can be stored per kg RCA. The authors also performed life cycle assessment (LCA) and prove that the proposed negative emissions value chain is capable of storing $93.6 \%$ of the $\mathrm{CO}_{2}$ used for carbonation and that the RCA produced has the lowest global warming potential compared to virgin and recycled cement. The authors extrapolate the results to show that it is possible to achieve $0.56 \mathrm{Mt}$ of $\mathrm{CO}_{2}$-eq. per year of negative emissions in Switzerland in 2050, when compared to the global potential of $500 \mathrm{Mt}$ of $\mathrm{CO}_{2}$-eq. per year.

Installing CCS on waste-to-energy can result in negative emissions due to the relatively large biogenic content of municipal solid waste. Integrating CCS in a waste-to-energy plant results in high investment and operation costs for the $\mathrm{CO}_{2}$ capture process, and currently there is a lack of incentives for negative carbon dioxide emissions. Torvanger (2021) explores possible business models for incentivizing the implementation of CCS from waste-to-energy. The business models are based on two main options: waste renovation customers being able and willing to pay for the additional cost of producing negative emissions of carbon dioxide directly, and through certificates or investments in CCS being supported by

\section{REFERENCES}

Bullock, L. A., James. R. H., Matter, J., Renforth, P., and Teagle, D. A. H. (2021). Global carbon dioxide removal potential of waste materials from metal and diamond mining. Front. Clim. 3:694175. doi: 10.3389/fclim.2021. 694175

IPCC (2018). Global Warming of $1.5^{\circ} \mathrm{C}$. An IPCC Special Report on the impacts of global warming of $1.5^{\circ} \mathrm{C}$ above pre-industrial levels and related global greenhouse gas emission pathways, in the context of strengthening the global response to the threat of climate change, sustainable development, and efforts to eradicate poverty, eds V. Masson-Delmotte, P. Zhai, H. O. Pörtner, D. Roberts, J. Skea, P. R. Shukla, A. Pirani, W. Moufouma-Okia, C. Péan, R. Pidcock, S. Connors, J.B.R. Matthews, Y. Chen, X. Zhou, M. I. Gomis, E. Lonnoy, T. Maycock, M. Tignor, and T. Waterfield. Available Online at: https://www.ipcc.ch/site/assets/ uploads/sites/2/2019/06/SR15_Full_Report_High_Res.pdf.

Krishnamurthy, S., Blom, R., Andreassen K. A., Middelkoop, V., Rombouts, M., and Borras, A. B. (2021). 3D printed pei containing adsorbents supported by carbon nanostructures for post-combustion carbon capture from biomass fired power plants. Front. Clim. 3:733499. doi: 10.3389/fclim.2021. 733499

Leeson, D., Mac Dowell, N., Shah, N., Petit, C., and Fennell, P. S. (2017). A technoeconomic analysis and systematic review of carbon capture and storage (CCS) applied to the iron and steel, cement, oil refining and pulp and paper industries, as well as other high purity sources. Int. J. Greenh. Gas Control 61, 71-84. doi: 10.1016/j.ijggc.2017.03.020

Svensson, E., Wiertzema, H., and Harvey, S. (2021). Potential for negative emissions by carbon capture and storage from a novel electric plasma government through tax rebates for negative emissions of $\mathrm{CO}_{2}$ or a guaranteed price.

Overall, CCS demonstrated to be an effective technological solution to provide negative emissions, especially in industries with feedstocks and fuels with a significant biogenic content. Leveraging on waste streams from industrial activities to provide CDR could allow for additional pathways. Implementing technological solutions for negative emissions comes at a high cost and might interfere with industry main products competing in global markets. Currently, financial incentives for CDR are lacking and there is a need to develop sustainable business models and new value chains to enable early movers. A clear and shared framework for carbon accounting and for guaranteeing the sustainability of bioresources is also fundamental. Material development with innovative manufacturing techniques, innovative process integration, and synergies with electrification all represent potential drivers toward cost-efficient negative emissions from industry. R\&D should be accompanied with industrial demonstrations to accelerate the deployment of the proposed technological solutions.

\section{AUTHOR CONTRIBUTIONS}

All authors wrote paragraphs for each article in the Research Topic that they edited. RM and LR wrote the introduction and conclusion section. All authors worked together to edit and improve the final text of the whole article.

\section{ACKNOWLEDGMENTS}

The editors would like to thank all the authors, reviewers, and associate editors who contributed to the Research Topic.

calcination process for pulp and paper mills. Front. Clim. 3:705032. doi: 10.3389/fclim.2021.705032

Tiefenthaler, J., Braune, L., Bauer, C., Sacchi, R., and Mazzotti, M. (2021). Technological demonstration and life cycle assessment of a negative emission value chain in the swiss concrete sector. Front. Clim. 3:729259. doi: $10.3389 /$ fclim.2021.729259

Torvanger, A. (2021). Business models for negative emissions from waste-toenergy plants. Front. Clim. 3:709891. doi: 10.3389/fclim.2021.709891

Conflict of Interest: The authors declare that the research was conducted in the absence of any commercial or financial relationships that could be construed as a potential conflict of interest.

Publisher's Note: All claims expressed in this article are solely those of the authors and do not necessarily represent those of their affiliated organizations, or those of the publisher, the editors and the reviewers. Any product that may be evaluated in this article, or claim that may be made by its manufacturer, is not guaranteed or endorsed by the publisher.

Copyright (c) 2021 Riboldi, Montañés, Nazir and Skorek-Osikowska. This is an openaccess article distributed under the terms of the Creative Commons Attribution License (CC BY). The use, distribution or reproduction in other forums is permitted, provided the original author(s) and the copyright owner(s) are credited and that the original publication in this journal is cited, in accordance with accepted academic practice. No use, distribution or reproduction is permitted which does not comply with these terms. 